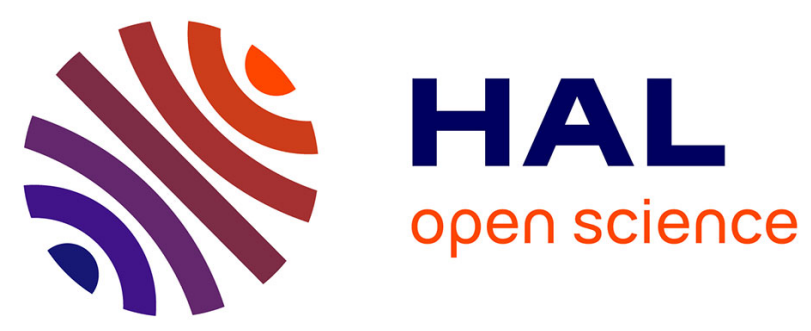

\title{
Assessment of an SOA for Burst Mode Pre-Amplification in Higher Speed PON reaching 30dB of Optical Budget
}

Jeremy Potet, Fabienne Saliou, Gaël Simon, Mathilde Gay, Laurent Bramerie, Philippe Chanclou, Monique Thual

\section{To cite this version:}

Jeremy Potet, Fabienne Saliou, Gaël Simon, Mathilde Gay, Laurent Bramerie, et al.. Assessment of an SOA for Burst Mode Pre-Amplification in Higher Speed PON reaching 30dB of Optical Budget. Optical Fiber Communication Conference (OFC 2021), Jun 2021, San Francisco, United States. 10.1364/OFC.2021.W1H.1 . hal-03327483

\section{HAL Id: hal-03327483 \\ https://hal.science/hal-03327483}

Submitted on 27 Aug 2021

HAL is a multi-disciplinary open access archive for the deposit and dissemination of scientific research documents, whether they are published or not. The documents may come from teaching and research institutions in France or abroad, or from public or private research centers.
L'archive ouverte pluridisciplinaire HAL, est destinée au dépôt et à la diffusion de documents scientifiques de niveau recherche, publiés ou non, émanant des établissements d'enseignement et de recherche français ou étrangers, des laboratoires publics ou privés. 


\title{
Assessment of an SOA for Burst Mode Pre-Amplification in Higher Speed PON reaching 30dB of Optical Budget
}

\author{
Jeremy Potet $^{(1)(2)}$, Fabienne Saliou ${ }^{(1)}$, Gaël Simon ${ }^{(1)}$, Mathilde Gay ${ }^{(2)}$, Laurent Bramerie ${ }^{(2)}$, Philippe Chanclou ${ }^{(1)}$, \\ Monique Thual ${ }^{(2)}$ \\ (1) Orange Labs, 2 Avenue Pierre Marzin, 22300 Lannion, France \\ (2) Univ Rennes 1, CNRS, Institut FOTON - UMR 6082, F-22305 Lannion, France \\ jeremy.potet@orange.com
}

\section{Introduction}

\begin{abstract}
We perform a 30dB optical budget burst mode transmission at 25Gbit/s with an EML and a DC$30 \mathrm{GHz}$ PIN pre-amplified with an SOA. We demonstrate that the SOA does not deteriorate the quality of the transmission. $\odot 2021$ The Authors
\end{abstract}

The ever-increasing bandwidth needs push the actual Passive Optical Network (PON) technologies to their limits. Currently, the recommendation for Higher Speed-Passive Optical Networks (HS-PONs) is still in discussion at the International Telecommunication Union (ITU-T) under G9804.1 [1]. Some specifications, such as the downstream wavelength $(1342 \mathrm{~nm} \pm 2 \mathrm{~nm})$, and bitrates $(50 \mathrm{Gbit} / \mathrm{s})$, are already decided. For the upstream, discussions are still ongoing in order to provide coexistence with the current deployed PON technology namely Gigabit capable PON (G-PON) and 10 Gigabit Symmetric capable PON (XGS-PON). As for legacy PONs, HS-PON uses Time Division Multiple Access (TDMA) on a point-tomultipoint topology and line rates of $12.5 \mathrm{Gbit} / \mathrm{s}$ or $25 \mathrm{Gbit} / \mathrm{s}$ are being discussed. From the very first discussions about HSPON, the use of Digital Signal Processing (DSP) was proposed [1] and widely explored [2] to meet the strong optical budget requirements at such bitrates. Legacy PONs did not use optical amplifiers and in this paper we propose to avoid the use of DSP and to investigate the impact of inserting an SOA in the upstream link [3] depicted in Fig. 1.a) and to study the impact of other ONU on the Optical Distribution Network (ODN) on the emitting ONU. The SOA will amplify burst mode transmitted signals coming from different ONUs at different power levels. In our discussions, a single SOA used as a pre-amplifier is located at the OLT side to share its costs. Consequently, the SOA amplifies every burst and off-level of every ONU connected to this OLT. We experimentally measured temporal and amplitude behavior of the SOA with these incoming optical bursts. We based the burst implementation following recommendations of the XGS-PON standard [4], as HS-PON specifications are not edited yet. These specifications are presented on Fig. 1.b). ONU off-level must not exceed $-45 \mathrm{dBm}$ and the dynamic range between the strongest and the weakest burst must be limited to $15 \mathrm{~dB}$. Time for Laser (Tx) enable, and Tx disable are equal (in bit time) to a minimum of $256 \mathrm{bits}$ in the best case. These times correspond to $10.24 \mathrm{~ns}$ at a bit rate of $25 \mathrm{Gbit} / \mathrm{s}$. To assess the increase of bitrates in PONs, the use of an SOA may become inevitable [5]. In this paper, we demonstrate that in a TDMA upstream PON at $25 \mathrm{Gbit} / \mathrm{s}$, the insertion of an SOA for optical amplification, has no impact on the quality of the link considering latency and optical power penalty measurements.

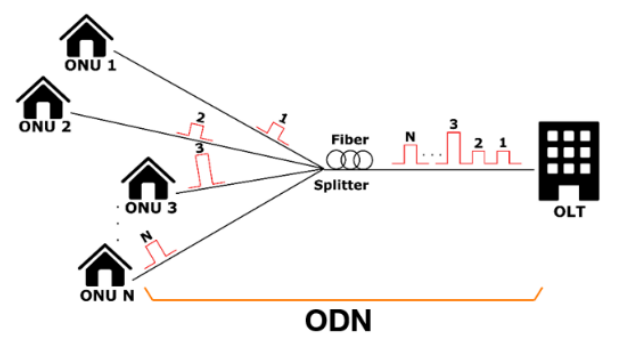

a)

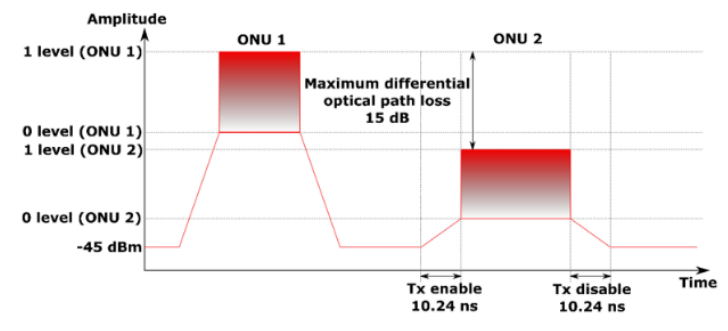

b)

Fig. 1: PON architecture in upstream a) and G9807.1 requirements for TDM-PON upstream b)

2. Experimental setup

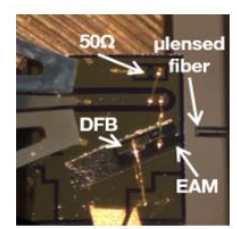

a)

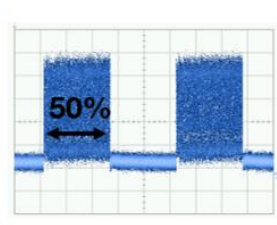

b)

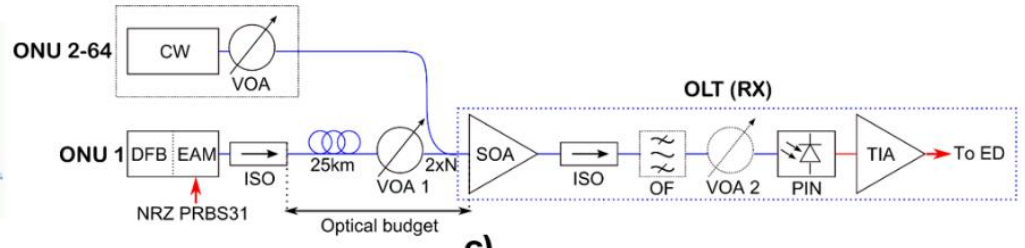

c)

Fig. 2: EML picture a), Burst at $25 \mathrm{Gbit} / \mathrm{s}$ with $50 \%$ duty cycle b) and $25 \mathrm{Gbit} / \mathrm{s}$ experimental setup with $\mathrm{SOA}$ in pre-amp c)

Fig. 2 presents the experimental setup used to characterize in real time the impact of the SOA on a 25Gbit/s Non-Return to Zero On-Off Keying (NRZ-OOK) burst-mode transmission. A Pulse Pattern Generator is used to generate data with a Pseudo Random Bit Sequence (PRBS) of length $2^{31}-1$ bits in order to modulate an O-band Externally Modulated Laser (EML) with a 
burst of 50\% duty cycle. This EML [6] is a single chip, showing two parts: a Distributed FeedBack laser (DFB) at 1310nm and an Electro-Absorption Modulator (EAM). As shown on Fig. 2.a), we use a micro-lensed fiber to couple the laser beam at the output of the chip associated with an isolator (ISO) to avoid back reflections. The EML is identified as the ONU 1 optical emitter. Before a Variable Optical Attenuator (VOA), zero or $25 \mathrm{~km}$ of fiber is inserted to assess the optical budget measurement. A $2 \mathrm{xN}$ coupler aims at mixing the signal from the ONU 1 and from a continuous source (CW) emulating the cumulative off-levels of up to 63 other ONUs on the ODN. The continuous source is identified as "ONU 2-64". With this coupler, we extract a part of the signal to measure the optical power and to visualize the input eye diagram. In this experimental setup, we use an SOA with a small signal gain of $19.2 \mathrm{~dB}$ and a Polarization Dependent Gain (PDG) of $1 \mathrm{~dB}$ when operating at a temperature of $20^{\circ} \mathrm{C}$, controlled by a thermoelectric cooler (TEC) and $400 \mathrm{~mA}$ of bias current. An optical isolator is inserted after the SOA in order to avoid back reflections. To reduce the amplified spontaneous emission (ASE), benefits of an optical filter (OF) are experimented at the SOA output, followed by a DC-30GHz PIN photodiode. Finally, to improve the amplitude of the electrical signal, a TransImpedance Amplifier (TIA) is inserted between the photodiode and the error detector (ED).

\section{Results and discussion}

First, we focus on the temporal aspect of the implementation of an SOA in PONs. The response time of the amplifier needs to be fast enough to adapt between consecutives bursts (Inter Burst Gap $\geq 2 \times 10.24 n s$ ). Fig. 3.a) and c) shows rising and falling edge of a square signal, b), corresponding to the burst envelop (without data). Enable and disable times (10-90\%) were set to $10.24 \mathrm{~ns}$. For clearer observations, we used an optical filter to reduce ASE on the signal passing through the SOA. Comparing envelops before and after going through the SOA, we observe no overshoot and no latency on the signal at the output of the SOA. Thus, according to those results, the implementation of an SOA in upstream PON will not increase the time response of the system.

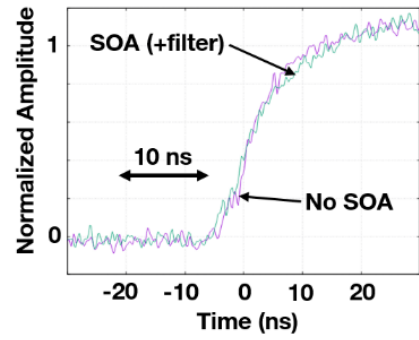

a)

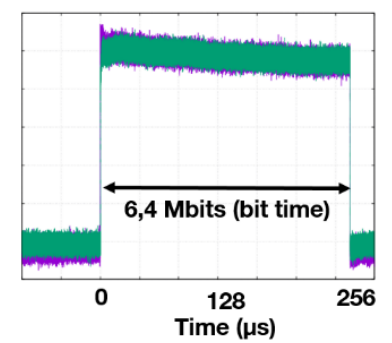

b)

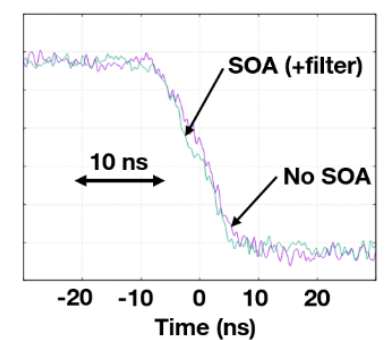

c)

Fig. 3 : Rising edge a) of a square signal b) and falling edge c) for a burst, before and after SOA, with Tx On and Tx Off of 10.24ns.

Then, the impact of the Amplified Spontaneous Emission (ASE) on the quality of the transmission is assessed. The BER is measured without any optical filter and with two different optical filters: one thin filter (0.9nm 3dB-bandwidth (BW)) and a coarse filter (13nm BW). Fig. 4.a) presents the BER versus the Optical Budget (OB) in back-to-back. Optical eye diagrams (Fig. 4.b) and c)) were measured at the SOA input and output for transmissions with a BER $<10^{-9}$, the extinction ratio (ER) reduction coming from the gain compression in presence of burst. We used a VOA (VOA 2 on Fig.2.c)) to maintain the same optical received power on the PIN despite the insertion losses of the filters and assess only the ASE noise filtering effect. A small improvement of $0.5 \mathrm{~dB}$ on the OB at $10^{-2}$ BER (HS-PON FEC limit) can be seen on Fig. 4.a) between the case without filter and with the $0.9 \mathrm{~nm}$ width filter. We can then conclude that the ASE noise reduction impact is negligible in comparison to the filters insertion losses. Filter and VOA 2 will then be removed in the following discussions.

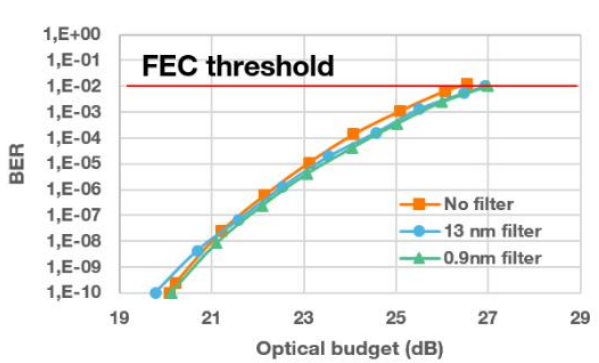

a)

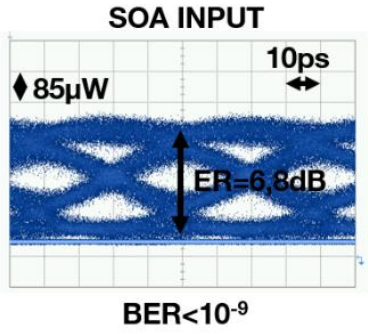

b)
SOA OUTPUT

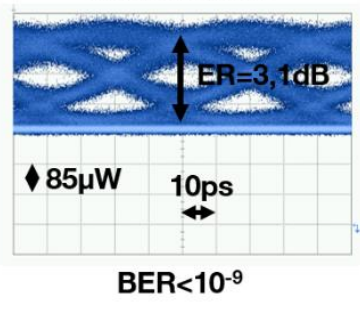

c)

Fig. 4 : BER vs optical budget without filter, with coarse filter and thin filter a). Eye diagram for error free at input of the SOA b), and at the output c).

We now investigate the impact of the amplified off-levels of ONU 2-64 on ONU 1. The ONU off-level power ("launched optical power without input to the transmitter" in [2]) specifies that the burst off-level must not exceed $-45 \mathrm{dBm}$ per ONU when the considered ONU is not supposed to send a signal between its bursts. In an upstream PON with 64 ONU to 1 OLT topology, amplified off-levels of ONU 2-64 will cumulate noise at the OLT receiver during ONU 1 time slot duration. The 2 to 64 ONUs total off-level power (defined as $\mathrm{P}_{0}$ ) can thus reach $-27 \mathrm{dBm}$ when they all emit $-45 \mathrm{dBm}$ at maximum. Taking into account the minimum propagation and splitting losses of the ODN (13dB losses), it would reach a maximum power of $-40 \mathrm{dBm}$ in front of the SOA. Three different cases are considered in this work: a reference case transmitting the signal at $1310 \mathrm{~nm}$ without continuous background power (no $\mathrm{P}_{0}$ ), a case with $\mathrm{P}_{0}=-58 \mathrm{dBm}$ corresponding to the off-level of one ONU and a case with $\mathrm{P}_{0}=-$ 
$40 \mathrm{dBm}$ corresponding to the sum of 63 ONU's off-levels. $\mathrm{P}_{0}$ is emitted at $1310.2 \mathrm{~nm}$ so $\Delta \lambda$ is equal to $0.2 \mathrm{~nm}$. Fig. 5.a) represents BER versus $\mathrm{OB}$ curves in these 3 cases. Also, we verify that $25 \mathrm{~km}$ fiber propagation does not induce penalties at a $\mathrm{BER}=10^{-2}$. The results show that for any of the 3 cases, the off-levels power does not degrade the performances. The same OB is obtained in all considered cases of $\mathrm{P}_{0}$ indicating that off-levels of ONUs are not damaging the transmission. Also, an optical budget higher than $30 \mathrm{~dB}$ was obtained at a BER of $10^{-2}$ in all cases, demonstrating the possibility to use an SOA as a pre-amplifier for burst mode upstream transmissions of HS-PONs with at least the N1 budget class (14-29dB).

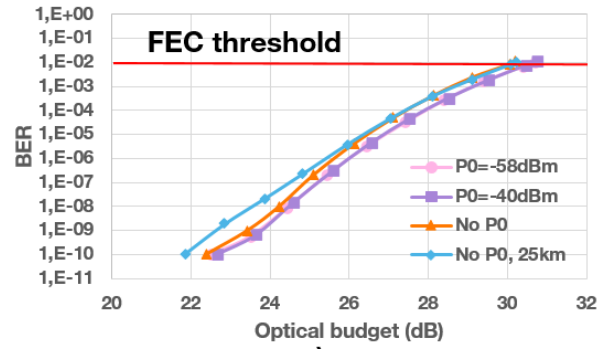

a)

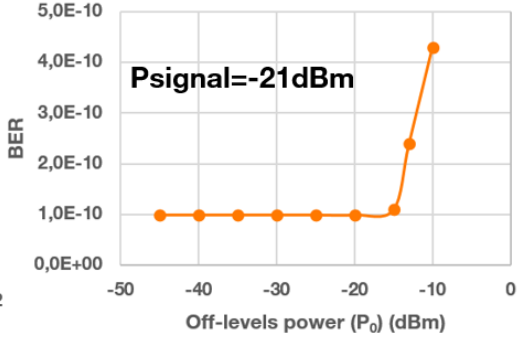

b)

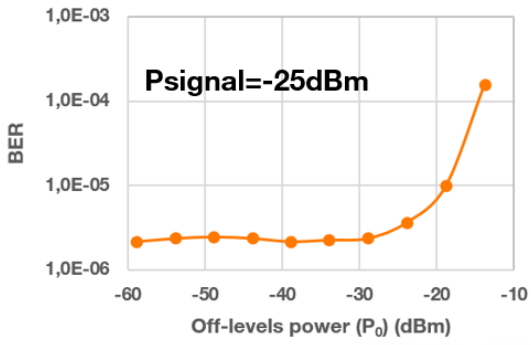

c)

Fig. 5 : BER vs optical budget for off-levels power of $-58 \mathrm{dBm},-40 \mathrm{dBm}$ and without $\mathrm{P}_{0}$ in back-to-back and with $25 \mathrm{~km}$ fiber propagation (a). BER vs Offlevels power in error free (b) and at BER start value of $2 \cdot 10^{-6}(\mathrm{c})$.

For more discussions, on Fig. 5.b) and c), we present the BER versus the off-levels power $\mathrm{P}_{0}$ at two different received powers corresponding to different BER values: error free and $2.10^{-6}$. The BER starts to deteriorate respectively at an off-levels power of respectively $-13 \mathrm{dBm}$ and $-27 \mathrm{dBm}$ which is a power more than $13 \mathrm{~dB}$ higher than the worst case of a 64 ONUs ODN $(13 \mathrm{~dB}=-$ $27 \mathrm{dBm}-(-40 \mathrm{dBm}))$. Consequently, no impact will be expected on the quality of the link.

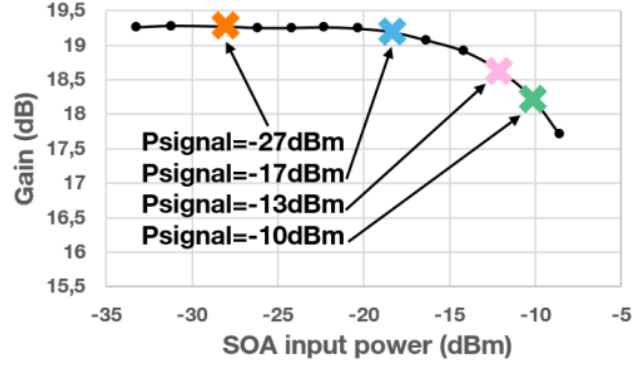

a)

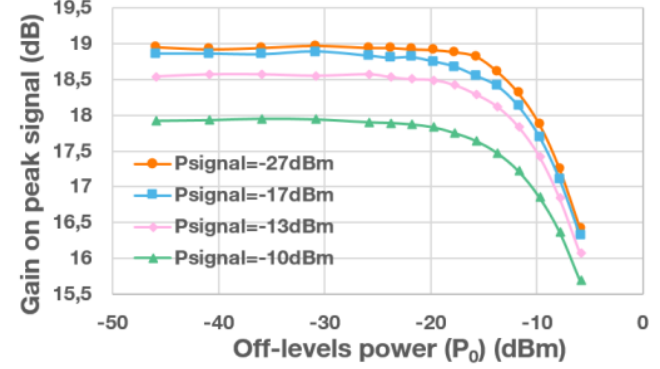

b)

Fig. 6 : Reference gain curve of the SOA at 1310nm (a), and (b) gain on peak signal vs off-levels power for 4 different signal power: $-27 \mathrm{dBm}$, $-17 \mathrm{dBm}$, $13 \mathrm{dBm}$ and $-10 \mathrm{dBm}$.

On Fig. 6.a) and b), we measure the effect on the SOA gain of amplifying both the burst signal of ONU 1 and the burst offlevels of ONU 2-64 corresponding to $\mathrm{P}_{0}$. Then Fig. 6.b), presents the gain of our amplifier versus off-levels power at 4 different signal input powers: $-27 \mathrm{dBm},-17 \mathrm{dBm},-13 \mathrm{dBm}$ and $-10 \mathrm{dBm}$. Fig. 6.a) shows the reference gain at $1310 \mathrm{~nm}$. Whatever the input signal power, we observe a gain degradation when $\mathrm{P}_{0}$ reaches more than $-20 \mathrm{dBm}$, well above the cumulated off-levels power of 63 ONUs $(-40 \mathrm{dBm})$. Higher gain penalties are also noticed when the input signal power increases: up to $1 \mathrm{~dB}$ of loss on the gain for an input signal power of $-10 \mathrm{dBm}$. This penalty is not reported on the quality of the transmission (Fig. 5.a)) as the PIN receiver remains in its error free regime over a large input power variation.

\section{Conclusion}

We performed a DSP free $25 \mathrm{Gbit} / \mathrm{s}$ NRZ transmission in burst mode with $25 \mathrm{~km}$ fiber propagation reaching more than $30 \mathrm{~dB}$ of optical budget and thus reaching the targeted N1 class budget (14-29dB) for future HS-PONs. We have investigated different aspects of the insertion of an SOA in HS-PON, such as the impact of ASE on the BER and the uselessness of an optical filter in such transmission. Amplifying the off-levels power (" $\mathrm{P}_{0}$ ") on the burst signals did not point out any blatant problem that can limit the use of SOAs for optical amplification of burst signals and this study is applicable for any PON technology.

\section{Acknowledgments}

The authors would like to thank Almae Technologies for the DFB-EAM.

\section{Reference}

[1] G.9804.1: Higher Speed Passive Optical Networks: Requirements; online: https://www.itu.int/rec/T-REC-G.9804.1-201911-I/en

[2] Houtsma, V., A. Mahadevan, N. Kaneda, and D. van Veen. 'Transceiver Technologies for Passive Optical Networks: Past, Present, and Future [Invited Tutorial]'. IEEE/OSA Journal of Optical Communications and Networking 13, no. 1 (January 2021): A44-55. https://doi.org/10.1364/JOCN.403500. [3] Borkowski, et al. 'Real-Time Burst-Mode Operation of an Integrated SOA-PIN/TIA Receiver for 25 Gbit/s/ $\lambda$ and Faster T(W)DM-PON'. In 2017 Optical Fiber Communications Conference and Exhibition (OFC), 1-3, 2017.

[4] G.9807.1: 10-Gigabit-capable symmetric passive optical network (XGS-PON); online: https://www.itu.int/rec/T-REC-G.9807.1-201606-I/en

[5] Bonk, R. 'SOA for Future PONs'. In 2018 Optical Fiber Communications Conference and Exposition (OFC), 1-3, 2018.

[6] Xing Dai et al, 'Versatile Externally Modulated Lasers Technology for Multiple Telecommunication Applications', IEEE Journal of Selected Topics in Quantum Electronics, Year: 2021 Volume: 27, Issue: 3 | Journal Article | Publisher: IEEE. 